\section{Pure science and the energy problem}

\section{Miranda Robertson, Chicago}

MucH the largest contribution of the Argonne National Laboratory to the problem of developing a new energy technology is its experimental liquidmetal fast-breeder reactor, and nuclear energy will continue to account for nearly half the total research expenditure of the laboratory. But recent shifts in the emphasis of federal funding are reflected in the expansion of research on a wide range of alternative and accessory approaches to the problem. At the same time, the laboratory (which is controlled by the United States Atomic Energy Commission) is beginning to feel the effects of a general movement to involve basic scientists in applied research, as interpreted by its new director, Dr Robert G. Sachs, now at the end of his first year at Argonne. A vigorous proponent of the view that fundamental scientists represent a national resource to be supported for reasons of enlightened self-interest, he believes that the time has now come to draw on that resource for the answers to a national problem. He also believes that a degree of mission-orientation need detraist from nobody's fundamental research pursuits. The effects of both-federal and local policy are nowhere better illustrated than in the birth of a new research project on solar energy in which Argonne personnel are collaborating with Dr Roland Winston from the Enrico Fermi Institute at the University of Chicago, where Dr Sachs holds a chair.

The outcome of this joint enterprise could be the development of a much more efficient solar energy collector than could be envisaged with known techniques; but it began as pure research on high energy physics. The problem to which the Winston advice was originally addressed was that of collecting Cerenkov radiation for the detection of rare electrons resulting from the $\beta$ decay of a $\lambda$ particle. The essential feature of the device was that it should not miss any radiation from the reaction.

Eventually, by departing from the principles of imaging optics, which limit the possible degree of concentration of the intensity of solar radiation to a factor of three, he arrived at an ideal light collector in the form of a cylindrical paraboloid with a theoretical maximum degree of concentration of ten times. The device represents a new principle as far as modern physics is concerned, although Professor Ricardo Levi Setti, a colleague of Winston's in the physics department, has discovered identical shapes in drawings of Descartes and in the individual eye-cups of the horseshoe crab. What Levi Setti also recognised, however, was that as well as having an interesting past the device has an important potential future as a concentrator of solar energy.

The problem of concentrating sunlight is only one of the obstacles to the utilisation of solar power to generate electricity, but it is one of the principal stumbling blocks in using it to heat and cool individual homes. The exploitation of solar energy for this purpose is already feasible and as a result of vigorous advocacy in the past year there has been an increase in the allozation of research funds as well as the institution of tax incentives for the conversion of buildings from conventional heating and cooling systems. But although solar heating is comfortably within the capacity of existing types of collector, cooling, which is much less efficient and in some areas in the summer stretches elestricity generation to the point of overload, is more marginal. The increased concentration factor of the Winston light collector may overcome the difficulty. Its other important advantage is that it can be designed so as to obviate the need for tracking the movement of the Sun across the sky, thus greatly reducing the complexity and the energy cost of the system. Winston's first model for a roof unit consists of a series of collectors shaped as paraboloid troughs which can be aligned with the Sun's trajectory so as to collect light for an average of eight hours a day.

The promise of the device has been endorsed by the allocation, in midfiscal year, of some $\$ 200,000$ from the United States National Science Foundation and the Atomic Energy Commission for feasibility studies. Winston and his collaborators at the Argonne are now working on such questions as how much light is actually collected by an ideal light collector made from nonideal materials and functioning under nonideal conditions. One of the problems being tackled is the development of what amounts to a new meteorological dictionary: for example, 'overcast' might mean something very different in terms of collectable solar radiation than it means in the week-end weather report.

\title{
Solar energy in suspense
}

Although almost everybody agrees that solar energy is a splendid idea whose time has come, a bill designed to hasten commercial application of solar heating and cooling technology has fallen foul of a jurisdictional squabble in the United States Senate and its passage has been delayed for several months while no less than five different committees have staked their claims on the legislation.

Passed by the House of Representatives in mid-February, the bill is designed to provide federal support for the development and testing of solar heating and cooling devices in private homes, office buildings, factories, schools and various other buildings. The idea is that the National Aeronautics and Space Administration (NASA) would be given some money to let contracts with industry for development and mass production of solar heating and cooling units, while the Department of Housing and Urban Development (HUD) would be responsible for carrying out prototype demonstrations to see how well the units perform in everyday use.

After being approved by the House-by a margin of 248 votes to two-the bill was referred to the Senate Committee on Aeronautical and Space Sciences which made a few amendments and passed it on March 13. In the meantime, how- ever, four other senate committeesCommerce, Labour, Interior and Banking, and Housing and Urban Affairs-all argued that the bill should come under their purview, so it was then referred to each of them separately.

The irony is that once the various committees have finished guarding their legislative jurisdictions, the bill which finally emerges will probably be similar to the version which was passed by the House, except for one important detail. The House bill would have provided $\$ 50$ million for the programme over the next five years, but the Senate Space Committee has suggested that NASA and HUD should each get $\$ 5$ million next year to carry out their parts of the enterprise and funding for future years should be left open for now.

As for the administration's attitude to the bill, Dr H. Guyford Stever, Director of the National Science Foundation and Science Adviser to the White House, has argued that although the demonstration scheme is a good idea, it is a little premature. The Administration has already proposed that $\$ 50$ million should be spent next year on solar energy research, and Stever reckons that it would be wise to wait until some of this effort bears fruit before rushing into a federally sponsored application programme. 